\title{
Application of recombination chambers for determination of neutron ambient dose equivalent at the door to the maze of linear accelerator vault
}

\author{
${ }^{1}$ Institute of Metrology and Biomedical Engineering, Warsaw University of Technology, Sw. A. Boboli 8, Warsaw, Poland \\ ${ }^{2}$ National Centre for Nuclear Research, Otwock-Świerk, Poland \\ e-mail: Edyta.Jakubowska@gmail.com
}

Recombination chambers and 2202D Studsvik-Alnor reference remmeter were used for determination of ambient dose equivalent, $\mathrm{H}^{*}(10)$ and its neutron and gamma components at the door to the maze of $15 \mathrm{MV}$ medical accelerator. The measurements were performed at opened and partly closed door. The results showed that the ambient dose equivalent rate was $76.2 \mu \mathrm{Sv} \mathrm{h}{ }^{-1}$ at the opened door and only $2.7 \mu \mathrm{Sv} \mathrm{h}{ }^{-1}$ at slightly opened door, $2.5 \mathrm{~m}$ from the entrance to the maze.

Key Words: recombination chamber, medical accelerator, photoneutrons.

\section{Introduction}

Radiotherapy with photon and electron beams represents the most spread out technique to control and treat tumor diseases. Nowadays, most medical accelerators produce beams with a maximum energy of between $15 \mathrm{MeV}$ and $25 \mathrm{MeV}$. However, the increase of electron and photon energy was joined with the generation of undesired photoneutrons (neutrons generated in the nuclear reaction between photons and target nuclei), which contaminate the therapeutic photon beam. 
Photon absorbed dose in locations outside the irradiation field, decreases very fast with the distance, as the therapeutic treatment requires, while, the neutron dose equivalent remains non-avoidable also in positions far from the irradiation field. Therefore, the neutron dose should be also taken into account when the shielding of the accelerator vault is considered.

This paper presents the results of neutron dose equivalent measurements performed at the door to the maze of linear accelerator vault in the Oncology Hospital in Warsaw. There were two targets of the study - the first and main reason was to investigate performance of our measuring system with recombination chamber, in comparison with a reference remmeter and the second - to proof, whether the patient irradiation could be performed with partly opened door. The second question appeared for practical reasons. The doors to the accelerator vaults are usually heavy and open slowly. This may cause an uncomfortable situation when children are treated under anesthesia and it would take a relatively long time to open the door for a medical doctor, in case of health problems of the patient during irradiation.

Radiation fields around medical accelerators are slightly contaminated with neutrons, generated by photon-neutron nuclear reactions. This concerns practically all the accelerators operating at maximum photon energy of $15 \mathrm{MeV}$ or higher. The photoneutron energy spectrum has a peak around $1 \mathrm{MeV}$, however, after the transmission through the accelerator head, neutrons have a distribution similar to those of the heavy shielded fission source [3, 4].

The level of neutron production varies around different treatment units due to differences in the construction of the treatment head and in the design of the treatment. Therefore, also the patient dose and the dose rate in the accelerator maze can be different, but practically almost no measurements are performed in radiotherapy departments, The main reason, to discourage medical physicists from making the measurements is lack of convenient measuring equipment for the routine use.

In this work we used the system with recombination chambers [2] for on-line measurements of ambient dose equivalent, $H^{*}(10)$.

\section{Materials and Methods}

Recombination chambers are high-pressure, usually tissue-equivalent, ionization chambers operating under condition of initial recombination of ions. This kind of recombination occurs within tracks of single ionizing particles. It does not depend on the dose rate and depends on local ionization density within the tracks of ionizing particles i.e. on radiation quality. 
Electrodes of the chambers are mostly made with a tissue-equivalent (TE) material. Gas in the chamber usually contains hydrocarbons; however, hydrogen-free chambers are also used as detectors with very low sensitivity to high-LET radiation.

The use of recombination chambers makes it possible to determine the total absorbed dose, which is proportional to the saturation current, and recombination index of radiation quality, $\mathrm{Q}_{4}[1,6]$, which can be used as an approximation of the radiation quality factor. Ambient dose equivalent $H^{*}(10)$ can be well approximated [1] by the product of the ambient absorbed dose $\mathrm{D}^{*}(10)$ and $\mathrm{Q}_{4}$.

$$
H^{*}(10)=D^{*}(10) \times Q_{4}
$$

In this work, measurements of $\mathrm{H}^{*}(10)$ were performed with a large recombination chamber of REM-2 type. This is a cylindrical, parallel-plate ionization chamber with 25 tissue-equivalent electrodes, a volume of $1800 \mathrm{~cm}^{3}$, a mass of $6 \mathrm{~kg}$ and an effective wall thickness of about $2 \mathrm{~g} / \mathrm{cm}^{2}$. The chamber of the same design, but with $\mathrm{Al}$ electrodes and filled with $\mathrm{CO}_{2}(2.8 \mathrm{MPa})$, is denoted as GW2. The chamber was used for determination of the gamma radiation dose rate. Moreover, the beam intensity was monitored, during the measurements, with the second tissue-equivalent recombination chamber.

Neutron ambient dose equivalent, $\mathrm{H}_{\mathrm{n}}{ }^{*}(10)$, was measured using a 2202D Studsvik-Alnor reference remmeter.

All the measurements were performed at the door to the maze of linear accelerator vault in the Memorial Cancer Center and Institute of Oncology (department at Wawelska street) in Warsaw.

The absorbed dose rate of the $15 \mathrm{MV}$ photon beam in the isocentre was $2.4 \mathrm{~Gy} / \mathrm{min}$.

The measurements were performed in two measuring positions - the first one was at the door, exactly in the door opening line, and the second point was in the corridor, $250 \mathrm{~cm}$ from the door (Fig. 1). The measurements in the first position were performed when the door was fully opened and at the second measuring point when the door was in one of three positions opened, closed or partly opened $(30 \mathrm{~cm})$. 


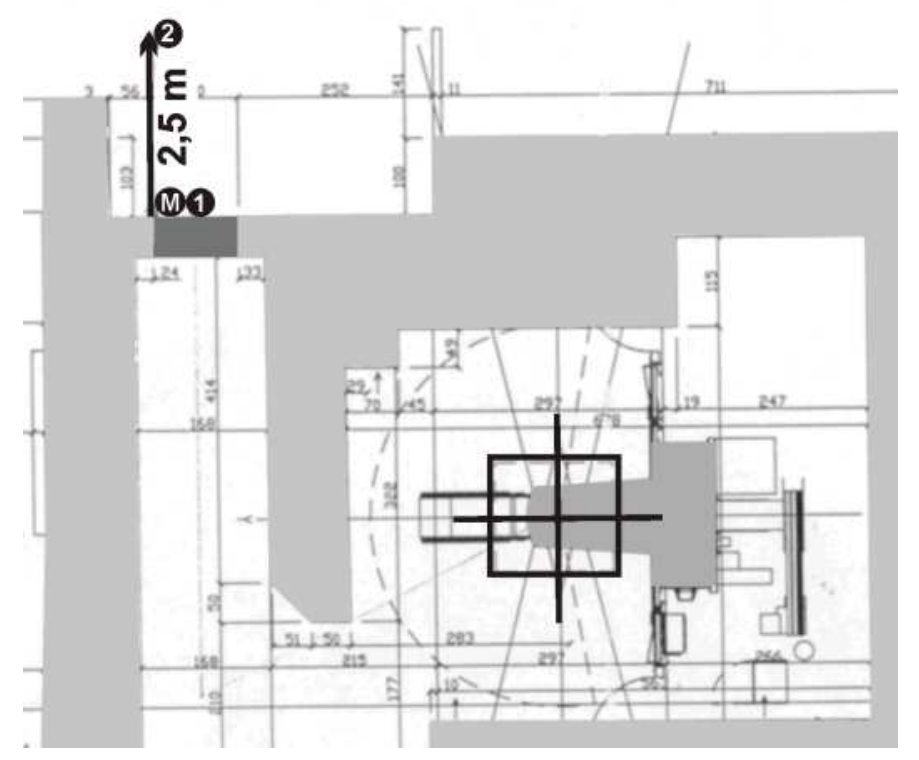

Figure 1. Measuring positions at the door to the accelerator maze

\section{Results and discussion}

The measured values of $H^{*}(10)$ and its neutron and gamma components are displayed in Table 1.

Table 1. Values of ambient dose equivalent rate at the door to the accelerator maze

\begin{tabular}{|c|c|c|c|c|}
\hline \multirow{2}{*}{$\begin{array}{l}\text { Dose } \\
\text { equivalent } \\
\text { rate } \\
\mu \mathrm{Sv} \mathrm{h}^{-1}\end{array}$} & \multirow{2}{*}{$\begin{array}{l}\text { At the } \\
\text { door } \\
\text { opened }\end{array}$} & \multicolumn{3}{|c|}{$250 \mathrm{~cm}$ from the door } \\
\hline & & opened & closed & $\begin{array}{l}\text { partly } \\
\text { opened }\end{array}$ \\
\hline $\begin{array}{l}\mathrm{H}^{*}(10) \\
(\mathrm{REM} 2)\end{array}$ & 76.2 & 25 & < 0.3 & 2.7 \\
\hline $\begin{array}{l}\mathrm{H}_{\mathrm{n}}{ }^{*}(10) \\
\text { (Studsvik) }\end{array}$ & 52 & 17.3 & 0.15 & 2.2 \\
\hline $\begin{array}{l}\mathrm{H}_{\nu}{ }^{*}(10) \\
(\mathrm{GW}-2)\end{array}$ & 24 & 7.5 & & $<0.5$ \\
\hline
\end{tabular}


The measurements near the opened door resulted in the total value of ambient dose equivalent rate of $\mathrm{H}^{*}(10)=76 \mu \mathrm{Sv} / \mathrm{h}$. The value was very close to the sum of neutron and gamma contributions, measured with the reference neutron remmeter and hadrogen free recombination chamber.

$$
H^{*}(10)=H n^{*}(10)+H \gamma^{*}(10)
$$

The contribution of gamma radiation to $H^{*}(10)$ was approximately $33 \%$. The value of the ambient radiation quality factor $\mathrm{Q}^{*}(10)$ was equal to $2.5 \mathrm{~Sv} / \mathrm{Gy}$, at the point of measurements.

In the corridor, with free access for people, the ambient dose equivalent $H^{*}(10)=25 \mu \mathrm{Sv} / \mathrm{h}$ and is three times smaller than at the door. When the shielding door was partly closed, the $\mathrm{H}^{*}(10)$ decreased to $2.7 \mu \mathrm{Sv} / \mathrm{h}$. Closing the door caused decrease of $\mathrm{H}^{*}(10)$ to the value below $0.3 \mu \mathrm{Sv} / \mathrm{h})$.

\section{Conclusions}

Measurements at the door to the maze made it possible to compare the neutron dose equivalent values measured with recombination chamber and 2202D Studsvik-Alnor remmeter. Measurements with both instruments were possible because of low dose rate and can be considered as one of practical tests of the recombination chamber response in the vicinity of medical accelerators. The serious advantage of the recombination chambers is that they practically do not suffer from saturation and dead-time effects. Therefore, they can be used also in the patient plane and some of them also in the beam, where remmeters with counters cannot properly operate.

The values measured at the door are relatively low, especially when the door is partly closed. The value of $\mathrm{H}^{*}(10)=2,7 \mu \mathrm{Sv} \mathrm{h}^{-1}$, recorded at rather high intensity of the photon beam, makes it possible to perform irradiation at slightly opened door, if there is justification for such irradiation. .

\section{References}

[1]. Golnik N. Recombination methods in the dosimetry of mixed radiation. Swierk (PL): Institute of Atomic Energy, Report No IAE -20/A. 
[2]. Golnik N., Tulik P., Bulski W. RADEM - recombination ambient dose equivalent meter for neutron dosimetry around medical accelerators. IFMBE Proceedings. 2009; 25/3: 484-486.

[3]. Králik M, Turek K. Characterisation of neutron fields around high-energy X-ray radiotherapy machines. Radiat. Prot. Dosim. 2004; 110(1-4): 503-507.

[4]. Thomas DJ, Bardell AG, Macaulay EM. Characterisation of a gold foil-based Bonner sphere set and measurements of neutron spectra at a medical accelerator. Nucl Instr. Meth. in Phys. Res A. 2002; 476: 31-35.

[5]. Zanini A, Durisi E, Fasolo F, Visca L, Ongaro C, Nastasi U, et al. Neutron spectra in a tissue equivalent phantom during photon radiotherapy treatment by Linacs. Radiat. Prot. Dosim. 2004; 110(1-4): 157-160.

[6]. Zielczynski M, Golnik N. Recombination index of radiation quality - measuring and applications. Radiat. Prot. Dosim. 1994; 52( 1-4): 419-422. 